\title{
O PROBLEMA DA AUSÊNCIA DA BIOÉTICA NO CURRÍCULO DOS CURSOS DE CIÊNCIAS BIOLÓGICAS NO BRASIL
}

\section{THE ABSENCE PROBLEM OF BIOETHICS IN THE CURRICULUM OF THE BIOLOGICAL SCIENCES COURSES IN BRAZIL}

\author{
Gabriela Bertti da Rocha Pinto \\ Rita Leal Paixão ${ }^{2}$
}

Resumo: O biólogo se depara com conflitos éticos desde seu ingresso na graduação. Nesse contexto, a adequada formação crítica para uma atuação plena desse profissional é necessária. Para suprir essa formação, a Bioética é preconizada como disciplina obrigatória no curso de Ciências Biológicas por contemplar o estudo das dimensões morais e condutas relacionadas às ciências da vida, ao "outro" e ao ambiente. Uma temática que discuta as relações éticas interespecíficas é imprescindível ao biólogo, isto é, a abordagem que ocorre no âmbito da bioética, ou mais especificamente, da ética animal e da ética ambiental. Com isso, esta pesquisa teve o objetivo de analisar os projetos pedagógicos dos cursos de graduação em Ciências Biológicas das universidades públicas brasileiras visando a detectar a presença das disciplinas de Bioética, Ética Animal ou Ética Ambiental em sua matriz curricular. Destacou-se a verificação de presença da Ética Animal nas ementas das disciplinas de Bioética existentes, considerando a emergência e relevância do tema que aborda as interações humanoanimal. Os resultados revelam que a maioria dos cursos não possui a disciplina de Bioética na matriz curricular, não há disciplinas específicas de ética animal e ética ambiental e quanto à análise das ementas das disciplinas de Bioética existentes, a maioria não contempla a Ética Animal. Deste modo, verifica-se a importância da revisão dos currículos, a inclusão da disciplina de Bioética e da temática ética animal, bem como de pesquisas que apontem o conteúdo da Bioética necessário para uma formação menos especista, propiciando debates mais qualificados sobre questões ambientais.

Palavras-chave: Ética Animal. Ética Ambiental. Ciências Biológicas. Currículo. Ensino Superior.
Abstract: The biologist is faced with ethical conflicts since joining the undergraduate program. In this context, the adequate critical training for a full performance of this professional is necessary. In order to fulfill this training, Bioethics is recommended as a compulsory subject in the Biological Sciences course, since it contemplates the study of the moral dimensions, decisions and behaviors related to the life sciences, the "other" and the environment. A theme that discusses interspecific ethical relationships is essential to the biologist, that is, the approach that occurs within the scope of bioethics, or more specifically, animal ethics and environmental ethics. The aim of this research was to analyze the pedagogical projects of undergraduate courses in Biological Sciences of Brazilian public universities aiming at detecting the presence of the disciplines of Bioethics, Animal Ethics or Environmental Ethics in its curricular matrix. The presence of Animal Ethics in the menus of the existing Bioethics disciplines was highlighted, considering the emergence and relevance of the theme that addresses human-animal interactions. The results show that most of the courses do not have the discipline of Bioethics in their curricular matrix, there are no specific disciplines of animal ethics and environmental ethics, and as for the analysis of the menus of the existing disciplines of Bioethics, most do not contemplate Animal Ethics. Thus, it is important to review the curricula for compulsory inclusion of the discipline of Bioethics and the theme of animal ethics, as well as future research that points out the content of Bioethics necessary for a less specific formation, leading to more qualified debates on environmental issues in society.

Keywords: Animal Ethics. Ambiental Ethics. Biological Sciences. Curriculum. Undergraduation.

\footnotetext{
${ }^{1}$ Doutoranda em Bioética, Ética Aplicada e Saúde Coletiva pela Universidade Federal do Rio de Janeiro. E-mail: <gabibertti@gmail.com>.

${ }^{2}$ Professora Titular do Instituto Biomédico da Universidade Federal Fluminense. Doutora em Saúde Pública pela Fundação Oswaldo Cruz. E-mail: <rita_paixao@uol.com.br>
} 


\section{INTRODUÇÃO}

Em meio ao apogeu do desenvolvimento científico, em 1970, o pesquisador em bioquímica oncológica Van Potter postula o termo Bioética, caracterizando-o como a ponte entre a ciência e as humanidades (Potter, 2016). É notada então a necessidade da discussão e intermediação dos conflitos éticos que esse avanço da ciência estava trazendo. As discussões iniciais sobre a Bioética possuíram um caráter antropocêntrico, se pautando principalmente em questões biomédicas, nas quais os animais não humanos e o meio ambiente novamente não entraram na "ordem do dia". Estamos no "Século da Ciência", no qual o conhecimento humano segue alcançando patamares inimagináveis e a Bioética se faz imprescindível como forma de alertar a sociedade sobre os riscos do seu avanço, impondo limites éticos e contribuindo para atitudes mais conscientes ante os desafios trazidos pelas novas descobertas (Lenoir, 1996).

No ensino, a Bioética abre caminhos para discussões críticas e análises que ajudam a discernir o que é bom e correto com base nos valores morais vigentes na sociedade contemporânea (Dória, 2011). A Bioética enquanto disciplina dispõe uma caixa de ferramentas para auxiliar os sujeitos na discussão de dilemas e na resolução de conflitos éticos (Schramm, 2002), tornando-se desta forma importante para qualquer área de formação. Por exemplo, na área das Ciências Biológicas essa caixa de ferramentas possibilita uma nova e ampla visão do conceito "Ambiente" e suas diversas interações.

O próprio Potter chamou a atenção para a necessidade de uma Bioética Global que precisa ser percebida não somente como uma ética além das fronteiras geográficas, uma ética mundial, mas também uma ética além das fronteiras traçadas entre humanos - animais - ambiente (Paixão, 2016).

Neste contexto, a reflexão quanto à uma formação qualificada durante a graduação em Ciências Biológicas merece destaque, devido à sua gama de atuação em campos onde incidem diversos conflitos éticos. O biólogo lida diretamente com as interações inter e intra-espécificas, com dilemas relacionados a teoria da evolução dos seres vivos, a reprodução, conflitos sobre o início da vida - com estudos sobre a criação in vitro da mesma-, e com isso colide com dogmas sociais de ordem político-religiosa. Logo no ingresso na graduação os estudantes encontram situações conflituosas como a de utilização de animais no ensino e na pesquisa. Essas situações que envolvem dilemas não são contestadas devido à naturalização desse tipo de prática de ensino e imposição de alguns paradigmas científicos. Compreendese que as modificações na maneira de pensar, nos hábitos fundamentais, nos grandes conceitos operantes e nas atitudes desenvolvem-se vagarosamente, portanto, é clara a importância do ensino nesse processo, já que é através da acumulação de experiências educacionais que são produzidas profundas mudanças (Tyler, 1978).

Ao negligenciar a formação ética direcionada ao meio ambiente e aos animais não humanos podemos dizer que a sociedade está traçando caminhos para futuros obscuros. Na área ambiental, por exemplo, sabemos que há uma enorme devastação das florestas e que existem problemas como as mudanças climáticas drásticas, dentre outros. Estes problemas de cunho ambiental poderiam ser evitados caso discussões éticas tivessem sido feitas no ambiente formador dos cientistas do futuro. Se a ética ambiental tivesse sido discutida, destacando a importância da manutenção do meio ambiente para as espécies, é possível traçar a hipótese de que o Tamanduá Bandeira (Myrmecophaga tridactyla) não estaria ameaçado de extinção, bem como a Jaguatirica (Leopardus Pardalis) ou a Araraúna (Anodorhynchus glaucus) que, infelizmente, já foi extinta, dentre muitas outras ainda estariam vivas e em seu habitat (Maas, 2017).

A discussão sobre a expansão e inclusão do critério da consideração moral dos seres vivos para serem sujeitos de direitos é um dos assuntos atuais entre teóricos da Academia, a qual precisa chegar também à sala de aula na graduação. A discussão sobre a posição social dos animais não humanos é um tópico dos mais necessários atualmente e é fundamental ressaltar a Ética Ambiental e Animal frente aos demais temas bioéticos, dada sua importância em tratar questões relacionadas a outros seres vivos tão ou mais complexos no que se refere a capacidades adaptativas e de sobreveviência que os animais 
humanos. Com todas as proezas científicas já realizadas, soa um tanto quanto rudimentar e ingênuo ainda julgar os animais não humanos como inferiores e os fazê-los instrumentos de desejos humanos.

Ao adentrar no curso de graduação em Ciências Biológicas a maioria dos currículos contempla logo no primeiro período uma disciplina ou atividade na qual se expõe o 'correto' manejo de cobaias e os demais procedimentos laboratoriais para tal manejo. Esse método retrógrado era uma prática comum para os laboratórios acadêmicos tal como um dogma para a igreja, pois ao tentar introduzir uma discussão ou questionar em disciplinas que se utilizam de animais não humanos há um grande furor e logo é feita uma manobra para encerrar tal assunto, deixando os estudantes sem resposta, quando não os ridicularizando (Tréz, 2008).

Na realização da experimentação animal, os animais não humanos são instrumentalizados, seguindo a lógica antropocêntrica, com experimentos feitos e justificados em prol do bem humano, ou melhor, pela superioridade humana, como exprime o trecho de Peter Singer, um dos principais teóricos no assunto:

As atitudes com os animais são um caso emblemático no paradigma antropocêntrico dominante atual, oriundas de séculos passados quando o "socialmente aceito" era que os animais não mereciam qualquer consideração moral. Não havia preocupação alguma com seu bem-estar, sofrimento ou no seu valor independente de interesses humanos. (Singer, 2002)

Se os estudantes são educados por esse modelo, sem contestações ou alternativas apresentadas, logo, tenderão a dar continuidade a tal modelo. No caso de se tornarem professores ensinarão o mesmo modelo que será replicado aos estudantes, gerando um ciclo anacrônico e despolitizado. No caso de se tornarem pesquisadores, continuarão a instrumentalizar os animais não humanos contribuindo para a opressão e morte de milhões de seres (Taylor, 2008).

Críticas a esse modelo retrógrado são constantemente tecidas. Podemos notar na política dos Parâmetros Curriculares Nacionais (PCN) para as Ciências Naturais, o apontamento para a necessidade de quebra de paradigma e destaque para a importância do ensino de ciências:

Durante os últimos séculos, o ser humano foi considerado o centro do Universo. $\mathrm{O}$ homem acreditou que a natureza estava à sua disposição. Apropriou-se de seus processos, alterou seus ciclos, redefiniu seus espaços. Hoje, quando se depara com uma crise ambiental que coloca em risco a vida do planeta, inclusive a humana, o ensino de Ciências Naturais pode contribuir para uma reconstrução da relação homem natureza em outros termos. (Brasil, 1998)

E vai além ao explicitar que esses cursos são favorecidos por lidar com temas que possuem diferentes teorias e que, portanto, deve-se promover um ensino que contemple todas as possibilidades:

O ensino de Ciências Naturais também é espaço privilegiado em que as diferentes explicações sobre o mundo, os fenômenos da natureza e as transformações produzidas pelo homem podem ser expostos e comparados. (...) contrapor e avaliar diferentes explicações favorece o desenvolvimento de postura reflexiva, crítica, questionadora e investigativa, de não-aceitação a priori de ideias e informações. Possibilita a percepção dos limites de cada modelo explicativo, inclusive dos modelos científicos, colaborando para a construção da autonomia de pensamento e ação. (Brasil, 1998)

As Diretrizes Curriculares Nacionais (DCN) e os PCN contribuem para guiar os Institutos de Educação Superior para uma formação mais uniforme e com uma visão mais macro dos cursos na tentativa de redução das disciplinas departamentais e compartimentais, não ignorando as particularidades regionais. No entanto, muitas disciplinas ainda estão sob espectro das correntes tradicionais de currículo e como cada universidade possui autonomia na construção de seus Projetos Pedagógicos, tanto institucionais quanto de curso, elas são apenas instrumentos e dependem então dos 
profissionais dessas instituições para fazer uma a leitura e terem um entendimento singular para implementação das mesmas.

No que tange ao curso em questão nesta pesquisa, a graduação em Ciências Biológicas permite ao formando inúmeras possibilidades de atuação no mercado de trabalho. Segundo o Conselho Federal de Biologia (CFBio) e de acordo com o estabelecido na mais recente Resolução $n^{\circ}$ 227/2010, que dispõe sobre a regulamentação das atividades profissionais e das áreas de atuação do biólogo, as áreas de atuação desses profissionais dividem-ses em Meio Ambiente e Biodiversidade, Saúde e, Biotecnologia e Produção. Ao todo, excluindo as repetições, são listadas 84 áreas de atuação. Somente dentro da área "Meio Ambiente e Biodiversidade" são listadas 47 atividades, que vão desde gestão de museus a paisagismo, perpassando por bioinformática a treinamento e ensino na área de meio ambiente e biodiversidade, dentre outros (CFBio, 2015).

A bioética encontra-se corretamente citada nas três grandes áreas de atuação do biólogo descritas na resolução mencionada acima, por ser uma temática transversal não poderia ser diferente. Com isso, fica explícita a necessidade da formação ética do biólogo em qualquer que seja a área em que venha atuar posteriormente à graduação. Dentre as preconizações para o curso temos como a mais recente o parecer de 2010 do CFBio a respeito do núcleo básico de temas, áreas e disciplinas e que institui a Bioética como disciplina do núcleo básico a ser cumprido pelo graduando devendo, portanto, estar presente no projeto pedagógico do curso.

Com isso, o parecer demandas às Instituições de Ensino Superior (IES) uma revisão na estrutura do curso para que contemple as exigências do perfil do profissional do biólogo, também delineado nas DCN, levando em consideração a identificação de problemas e necessidades atuais e prospectivas da sociedade, assim como da legislação vigente. Bem como deve contemplar os conteúdos específicos descritos nas diretrizes curriculares de Ciências Biológicas a respeito de cada ano do grau acadêmico do curso.

O perfil do sujeito bacharel, por exemplo, é concentrado no mercado de trabalho, na área técnica e empresarial, já que entende-se que ele será responsável por correlações entre ciência, tecnologia e sociedade (CFBio, 2010). Deste modo não deve ser isento e/ou privado da discussão e do ensino sobre Ética Aplicada e Bioética, como determinado nas DCN no tópico de competências e habilidades que este profissional deve possuir:

h) Pautar-se por princípios da ética democrática: responsabilidade social e ambiental, dignidade humana, direito à vida, justiça, respeito mútuo, participação, responsabilidade, diálogo e solidariedade;

i) Reconhecer formas de discriminação racial, social, de gênero, etc. que se fundem inclusive em alegados pressupostos biológicos, posicionando-se diante delas de forma crítica, com respaldo em pressupostos epistemológicos coerentes e na bibliografia de referência. (BRASIL, 2001)

Seguindo esse trecho, temas como as questões de gênero e a racial, são diretamente relacionadas ao tocante da Bioética em sua interseccionalidade 3 . Não basta bom senso para lidar com questões que versam sobre a eticidade da condução de pesquisas com seres vivos e o meio ambiente, sobre as violências nas relações de trabalho e ensino ou sobre as questões da morte e do controle sobre a vida na área da saúde. A falta da ética na ponderação para tomada de atitudes que visem à resolução de conflitos dessa magnitude pode gerar e gera resultados catastróficos, tanto para o presente quanto para o futuro.

Como exemplo, um caso que foi destaque na grande mídia, valida essa afirmação. Uma das atividades destinadas ao profissional biólogo é o de gestor de zoológicos.A eticidade desse ambiente deveria ser de temática obrigatória de contestação durante a graduação, uma vez que está diretamente relacionada a esta profissão. Em 2016, foi midiatizado o caso de um menino de 4 anos que não obedeceu

\footnotetext{
${ }^{3}$ Conceito elaborado por Kimberle Crewshaw, que define a interseccionalidade como "formas de capturar as consequências da interação entre duas ou mais formas de subordinação: sexismo, racismo, patriarcalismo." Crenshaw, Kimberle. Demarginalizing the Intersection of Race and Sex: A Black Feminist Critique of Antidiscrimination Doctrine, Feminist Theory and Antiracist Politics. The University of Chicago Legal Forum. jan 1989, p. 140: $139-167$.
} 
às normas de segurança, ultrapassou a proteção e caiu na cela do Gorila Harambe em um zoológico em Cincinnati nos Estados Unidos. O resultado foi catastrófico: após dez minutos de discussão sobre qual ação deveria ser feita, a execução de Harambe foi a escolhida. A consideração da situação como uma ameaça à vida do menino foi o argumento utilizado pela equipe de resposta contra riscos de animais para tal feito (Simpson, 2016).

Aqui temos claramente um escalonamento de valores e a escolha prioritária da consideração moral e de direitos para com os animais humanos. Este é o mesmo recorte que é dado desde o início da graduação em Ciências Biológicas sem que haja ao menos uma possibilidade de contestação desse panorama, pelo contrário, evita-se ao máximo a discussão de temas considerados polêmicos ou julgados como irrelevantes.

O currículo é socialmente definido e construído por membros das comunidades acadêmicas, membros estes que podem ter outra prerrogativa de valores morais que não seja a vigente, portanto, é possível que um currículo de curso não especista promova uma mudança de paradigma. Através de uma mudança curricular em uma Universidade pode-se gerar uma mudança na sociedade ou ao menos promover o debate sobre os atuais paradigmas para sejam repensados e se torne cada vez mais inclusiva. Visando o respeito à autonomia e o respeito aos seres vivos, essa proposta de ensino permite abranger o ambiente integral e os animais não humanos no processo educacional, colaborando para um ensino mais inclusivo e possibilitando aos futuros biólogos, pesquisadores e professores uma maior consciência crítica político-social, além de os capacitar para lidarem com conflitos e dilemas morais advindos da prática profissional.

Tendo em vista a importância da graduação em Ciências Biológicas para que as questões ambientais possam ser socialmente melhor discutidas, o presente artigo tem o objetivo de apresentar subsídios acerca da oferta das disciplinas de Bioética em relação à formação do graduando desse cursono Brasil.

\section{METODOLOGIA}

A fim de se ter acesso aos projetos pedagógicos do curso de Ciências Biológicas - que constituíram a amostra desse estudo -, os dados sobre as universidades foram obtidos por busca ativa, através de consulta interativa da plataforma virtual 'e-MEC', uma base de dados oficial e única de informações relativas às Instituições de Educação Superior e cursos de graduação do Sistema Federal de Ensino. Os dados do cadastro "e-MEC" guardam conformidade com os atos autorizativos das instituições e cursos de educação superior, editados com base nos processos regulatórios competentes da Portaria Normativa MEC $n^{\circ}$ 40/2007. Foram consideradas IES públicas brasileiras e gratuitas que ofertam o curso de graduação cadastrado como 'Ciências Biológicas', incluindo todas as ênfases de formação ramificadas do curso em questão. Esse banco de dados foi escolhido por ser o mais completo e oficial dentre as fontes e, conforme explicitado na plataforma, é facultado às IES pertencentes ao sistema estadual de ensino, reguladas e supervisionadas pelo respectivo Conselho Estadual de Educação, fazer parte do cadastro eMEC.

Como critério de inclusão das IES na pesquisa, elas devem ser da categoria administrativa pública e não pode haver cobrança de mensalidade, ou seja, deve ser gratuita e brasileira. $O$ curso de Ciências Biológicas deve ser devidamente cadastrado e autorizado pelo MEC, conforme o Decreto $n^{\circ}$ 5.773/2006, totalmente presencial e em atividade. Os graus acadêmicos analisados foram bacharelado e licenciatura plena e,na existência das duas modalidades na mesma Universidade, ambas foram incluídas. Para fim de análise quantitativa, no caso de oferta do curso da mesma modalidade em diferentes períodos (integral, matutino, vespertino ou noturno) foi contabilizado um projeto pedagógico do curso (PPC), dado que o curso possui apenas um mesmo projeto pedagógico para o mesmo grau acadêmico com a mesma matriz curricular, desta forma não ocorreu prejuízo à pesquisa. Os diferentes campus também foram quantificados como IES diferentes entre si por possuírem PPC distintos.

Após levantamento das IES, foi feita uma busca ativa dos projetos pedagógicos do curso de Ciências Biológicas nos sítios online das Instituições previamente selecionadas, sendo considerado apenas o mais recente em vigor. Nos PPC devem obrigatoriamente constar as disciplinas ofertadas pelo curso e as 
grades curriculares por período, além de que devem estar sempre disponíveis e de fácil acesso da população - conforme o decreto do MEC (BRASIL, 2007).

Foi feita uma análise das matrizes curriculares para verificar a incidência das disciplinas de Bioética, Ética Animal e Ética Ambiental em cada um dos cursos. Posteriormente, foi feito um levantamento das ementas das disciplinas de Bioética existentes, sendo verificados todos os tópicos do documento com uma atenção especial à bibliografia da mesma a fim de localizar a temática 'Ética Animal' e quantificar os pontos abordados. Como critério de inclusão, foram utilizadas três expressões-chave durante a busca ativa na ementa, sendo elas: ética em pesquisa com animais; pesquisa com seres vivos e pesquisa com animais. Houve a compreensão de que a presença dessas expressões abrange a discussão ética sobre os animais não humanos. Quanto à bibliografia sugerida, além das expressões, procurou-se localizar autores já consagrados na área.

\section{RESULTADOS}

Foi identificado o total de 261 Instituições de Ensino Superior públicas, presenciais e gratuitas no Brasil que possuem o curso de Ciências Biológicas nos graus acadêmicos de bacharelado, licenciatura plena ou ambos. Do total de IES encontradas estão presentes três categorias administrativas em organização acadêmica: Universidade Estadual, Universidade Federal e Instituto Federal. Do número total, a maioria das Instituições são Universidades Estaduais, contabilizando 115 unidades, seguida das Universidades Federais com 95 e os Institutos Federais que somam 52 unidades.

Quanto ao levantamento dos projetos pedagógicos do curso, foram encontrados 350 PPC de Ciências Biológicas, sendo 112 no grau acadêmico de bacharelado e 238 na modalidade licenciatura plena.

Analisando a presença ou ausência da disciplina de Bioética na matriz curricular dos projetos, dentre os 350 PCC totais obtidos, apenas 108 possuem a disciplina de Bioética, ou seja, 69\% dos PPC não possuem a disciplina. Além disso, nenhuma disciplina intitulada de Ética Animal ou Ética Ambiental foram encontradas nas grades curriculares da presente pesquisa.

Dentre as disciplinas de Bioética existentes também foi quantificada a categoria de oferta, podendo constar como obrigatória ou eletiva. Quanto a esse tópico, em 77 dos cursos essa disciplina consta como obrigatória no currículo e em 31 como disciplina eletiva. Na etapa seguinte, a fim de investigar sobre a presença da discussão sobre a temática dos animais não humanos, foi encontrado que em apenas 37 dos 108 projetos totais que possuem a disciplina, aparece no programa a abordagem da temática (PINTO, 2016).

\section{DISCUSSÃO}

Os resultados encontrados nessa pesquisa apontam que 69\% dos PPC não possui a disciplina de Bioética na matriz curricular, o que demonstra necessidade de estímulo dessa implementação devido à grande lacuna na formação do biólogo. As diretrizes curriculares nacionais do curso de Ciências Biológicas preconizam uma formação ética do sujeito bacharel como conteúdo básico, como podemos observar no trecho exposto na categoria de Fundamentos Filosóficos e Sociais:

Reflexão e discussão dos aspectos éticos e legais relacionados ao exercício profissional. Conhecimentos básicos de: História, Filosofia e Metodologia da Ciência, Sociologia e Antropologia, para dar suporte à sua atuação profissional na sociedade, com a consciência de seu papel na formação de cidadãos. (Brasil, 2001, p.6)

Porém, este é o único ponto que versa, indiretamente, sobre a formação Bioética nas diretrizes, e que se dá muitas vezes através da ética deontológica, ao relacionar exclusivamente a ética às normativas de curso. Dessa maneira não há aprofundamento na categoria filosófica. Compreende-se que um currículo que visa contemplar os fundamentos da Filosofia deveria levar em consideração o pluralismo e a diferença moral da sociedade para chegar ao objetivo de formar sujeitos "com a consciência de seu papel na formação de cidadãos" apresentando diferentes teorias e não apenas reproduzindo normativas.

Outro documento mais recente, Parecer $N^{\circ}$ 01/2010, que busca orientar na construção do curso foi estabelecido pelo conselho da profissão em 2010. Neste são propostos novos requisitos mínimos, 
sugestões de conteúdo, cargas horárias e componentes curriculares/disciplinas para nortear a elaboração do PPC, visando possibilitar melhor formação para a atuação profissional com foco em pesquisas, projetos, emissão de laudos e pareceres nas áreas de meio ambiente, saúde e tecnologia, independente do grau acadêmico. Nesse parecer, na parte correspondente ao núcleo de formação básica, a Bioética é estabelecida como disciplina obrigatória para o curso, apresentada no tópico 5 de Fundamentos Filosóficos e Sociais juntamente com Filosofia, Sociologia e Antropologia (CFBio, 2010). Vale ressaltar que autores apontam que a própria disciplina de Bioética poderia ser o gatilho para se repensar a estrutura em que se dá a formação profissional do indivíduo biólogo, segundo Diniz (2002) Pesquisar, ensinar ou escrever sobre bioética implica em um repensar profundo sobre o nosso próprio lugar no mundo moral como único caminho para ampliar nosso horizonte moral do possível.

Para lidar com o conflito moral em ciências da saúde e educação, bem como com todas as paixões que acompanham os conflitos, é necessário antes se ter realizado o movimento de reflexão sobre as moralidades (DINIZ, 2002). A Bioética compreende, como um todo, investigações necessárias para uma administração responsável da vida, sendo vida definida como humana ou não humana, animal ou vegetal, bem como a relação destes personagens com o meio ambiente que atuam. Por ser transdisciplinar, englobando Biologia, Medicina, Filosofia e Direito, é neste ponto que pode ocorrer interpretações equivocadas (DINIZ, 2001). Tomar a bioética com estritamente legalista e de recomendações éticas prescritivas é reduzir drasticamente todo o escopo que ela permeia, desta forma fazendo um recorte limitado de conhecimentos e possibilidades. As grandes áreas do conhecimento que compõe a bioética devem ser discutidas conjuntamente, já que a não dissociação dos conteúdos é necessária para que não se reproduza a antiga maneira compartimentada de ensinar e aprender. Aquela que não facilita a construção de pontes entre os saberes, aumentando a distância entre a teoria e a prática, acaba por desestimular o graduando no processo de aprendizagem e esse posicionamento também reflete em suas relações sociais.

Do ponto de vista de sua natureza, o currículo define-se como um produto, um resultado de planejamento em busca de um objetivo de formação que através de uma série de experiências de aprendizagem dos estudantes, em função de um plano previamente determinado, irá se concretizar na prática, portanto, deveria ser flexível e transversal (Cunha, 2010). Como podemos observar pela ausência da disciplina de Bioética em 242 do total de 350 PPC analisados, ainda estamos de frente com uma lógica burocrática do desenvolvimento e reformulação do currículo. Existem exemplos fora do Brasil que inauguraram uma perspectiva moderna curricular na área da saúde, como a Universidade de McMaster no Canadá e a respeitada Universidade de Harvard nos Estados Unidos da América:

Reestruturaram-se completamente em termos curriculares, colocando como um dos pilares da formação dos médicos a dimensão ética, não como disciplina a mais, mas como uma dimensão que está presente em todas as atividades estudantis e profissionais daquele que atua na área de saúde (Masetto, 2003).

Passados dezessete anos da aprovação das Diretrizes Curriculares Nacionais, as Universidades tiveram tempo para adequação às novas prerrogativas e para avaliação de seus cursos. Em análise sobre o ano de formulação ou reformulação dos projetos pedagógicos levantados na presente pesquisa, observa-se que a maioria que contempla a disciplina em questão são recém-inaugurados, com menos de quatro anos de formulação. Como, por exemplo, o projeto do Instituto Federal de São Paulo, campus São Roque, reformulado em dezembro de 2015, momento no qual passou acontemplar a disciplina de Bioética como obrigatória nas duas modalidades oferecidas. Porém, o quadro parece estagnado quando comparamos os dados dessa pesquisa com uma pesquisa anterior, realizada com base apenas em Universidades Federais, a qual apresentou que 50 por cento das matrizes curriculares dispunham da disciplina (Dória, 2011). Os dados da presente pesquisa também apontaram que no caso do tema "Ética Animal" a lacuna na formação é ainda maior, com apenas 37 currículos contemplando essa discussão.

Os resultados atuais indicam a perpetuação do descaso e despreocupação das instituições em dois pontos principais sendo (i) a inadequação com as Diretrizes, bem como (ii) a negligência com o debate bioético, mostrando que a maioria das Universidades continua em local mantenedor de seus antigos 
princípios, valores e preceitos. Sendo a Universidade, o local que tem o objetivo formar profissionais com consciência crítica e serum ambiente que interfere e influencia diretamente na sociedade, é imprescindível que se atualize e busque novos posicionamentos éticos e moralidades como missão institucional e, com isso, avaliar e rever a estrutura geral e os currículos dos cursos oferecidos torna-se uma tarefa necessária.

Os resultados também nos chamam a atenção para as diferenças quanto aos graus acadêmicos. Dentro das modalidades de formação em Ciências Biológicas cabe tanto ao bacharel quanto ao licenciando pensar e agir em conformidade ética para com o meio ambiente e os animais não humanos e também contribuir para a exclusão da desigualdade de consideração entre as espécies. Os PPC de bacharelado que contemplam a disciplina de Bioética somam apenas 41 do total de 112 da modalidade, explicitando uma lacuna na formação bioética numa grande parcela de futuros bacharéis.

Como dito anteriormente, o profissional bacharel em biologia, que se pretende pesquisador, é responsável pela integração entre a ciência e a sociedade através da realização de pesquisas que visam o avanço tecno-cientifico. Concomitante a esse avanço tecnológico estão presentes questões éticas importantíssimas como, por exemplo, o potencial de destruição de armas biológicas, as agressões ao meio ambiente por conta da alta taxa de eliminação de gases poluentes por parte de indústrias ou mesmo em relação à justiça distributiva no tocante do direito ao acesso à novos medicamentos e tecnologias em saúde pela população mais vulnerada. A ausência da oferta da disciplina em $63 \%$ de matrizes curriculares para bacharéis representa, aproximadamente, a formação de 2.361 cientistas por ano que não tem contato com debates ambientais e dilemas bioéticos em sua formação, não sendo capacitados profissionalmente para a construção de argumentos e análises de conflitos éticos. O debate da Ética Ambiental tem que ser levado a destaque urgentemente e garantir a existência mínima da disciplina de Bioética é uma questão de justiça.

O maior número de cursos de licenciatura plena (com relação às demais modalidades), sendo estes68\% do total, pode ser explicado pelo fomento e financiamento do Governo Federal que vem ocorrendo há alguns anos. A carência de professores no país tem levado as universidades a aumentar o número de cursos de licenciatura e benefícios a quem busca por esse tipo de formação (Czelusniak, 2011), além da criação e ampliação dos Institutos Federais de Educação (IFE) -que somam 20\% das IES analisadas neste estudo -, metas alcançadas pelo programa de expansão da Educação Superior e Profissional e Tecnológica do Ministério da Educação.

Dos 238 PPC de licenciatura plena 171 não dispõe da disciplina de Bioética. Isso serve como demonstração para o fato de que não está havendo o favorecimento das competências profissionais necessárias ao licenciando, desta forma prejudicando a formação destes futuros professores, bem como dos seus futuros educandos.

Quanto a essa modalidade deveria haver cuidado redobrado na formulação de currículos e projetos pedagógicos, uma vez que estes graduandos poderão vir a ser os professores do ensino básico após graduados. Um professor tem influência direta na formação intelectual e social do aluno, bem como de uma sociedade, pois a educação transforma as pessoas para que elas então possam mudar a realidade presente (Freire, 2009).

É notado que a preparação dos graduandos de licenciatura em Biologia para a tomada de decisões e manejo de conflitos é falha (Silva, 2002). As Ciências Biológicas constituem um campo que tem arraigados diversos dilemas. Portanto, encontra-se uma grande importância na preparação dos professores de Ciências e Biologia para lidarem com estas questões em sala de aula. Como mostra a pesquisa de Silva, realizada em 2008 acerca da percepção dos estudantes de licenciatura em Ciências Biológicas, os graduandos têm a consciência de seu importante papel social:

Os licenciandos admitem que a formação ético-moral é fundamental para a formação do estudante; creem que a escola, bem como outros ambientes sociais vinculados ao estudante são corresponsáveis por esta formação. Para eles, há uma concordância que estudantes do Ensino Fundamental e Médio estejam em pleno desenvolvimento de sua personalidade moral, além disso, acrescentam o 
importante papel da disciplina de Ciências e Biologia como espaço de promoção de valores éticos-morais. (Silva, 2008)

Visto que os futuros professores têm o entendimento de que a disciplinas de Ciências e Biologia possuem destaque na formação ética do estudante, fica o questionamento de como o ensino se dará de forma plena tendo que a educação é uma teoria do conhecimento posta em prática e os licenciandos atualmente não possuem formação teórica necessária para a concretização satisfatória desse ato.

Garantir minimamente a existência da disciplina de Bioética com caráter laico e abrangência ambiental é uma questão de justiça. A privação do debate não influencia tão somente após a conclusão do curso no que diz respeito à atuação profissional, impede também a contestação e análise crítica das condições da própria graduação. O que deve se alterar, portanto, são os currículos de curso de Ciências Biológicas, que reproduzem o paradigma antropocêntrico da sociedade. Estamos observando atualmente os resultados da negligência ambiental: estações climáticas do ano com temperaturas extremas, gerando danos diretamente para o animal humano;o alto índice de câncer de pele por causa da maior exposição os raios solares advindo da destruição da camada de ozônio, principal responsável pela filtração dos mesmos; entre outros (Popim et al, 2008).

A ausência desse debate pode ser um dos fatores que contribuintes para o dado de 2009, que aponta 150 municípios da Amazônia com 80\% da área de floresta desmatada para a criação de pastos para gados de corte (Riveiro et al, 2009), criação esta que mata cerca de 26 milhões de animais por ano para o consumo humano (IBGE, 2013). Dados indicam que a produção de hum quilograma carne gasta em média 15 mil litros de água (Florios, 2014), litros que poderiam salvar pessoas que morrem de sede ou que ainda não possuem saneamento básico. Sendo a questão garantir direitos básicos somente quando se refere aos animais humanos, a condição degradante em que vivem muitas pessoas deveria ser levada em consideração. Deste modo, reclamações e apelos pela redução de danos ao meio ambiente deixariam de ser exigências exclusivas de ambientalistas para serem preocupações compartilhadas com defensores de direitos básicos e priorizadas como políticas sociais. Portanto, a adoção de uma moralidade e uma justiça que amplie a esfera da moral para contemplar todos seres vivos em geral seria o necessário para salvar o planeta e a nós mesmos.

\section{CONSIDERAÇÕES FINAIS}

A Bioética é fundamental na formação do biólogo, já que ela empodera os sujeitos na tomada de decisões e posicionamentos relacionados tanto à profissão quanto às relações sociais. Porém, para que os biólogos tenham a capacidade de compreender, requerer e lutar para tal capacitação, deve ser possibilitado que o tema esteja presente e seja fomentado no curso. Os graduandos, ao ingressarem, já possuem uma opinião sobre certos temas tocantes à Bioética, como por exemplo, no caso da experimentação animal. Esse conhecimento pré adquirido pode possuir diversos vieses, dentre eles, o midiático, do qual a posição dominante na sociedade se utiliza para manter a estrutura da mesma. Ao serem apresentados a diferentes correntes teóricas, valores e moralidades poderão pensar e argumentar de maneiras diferenciadas e embasadas teoricamente.

Se a Universidade é um espaço emancipatório e libertador, além de um cenário de socialização da mudança (Fávero, 2006) e o currículo uma construção social, vinculado à determinada sociedade e às relações com o conhecimento (Silva, 1990) é devido a esta estrutura pensar em mudanças. O projeto pedagógico de curso sendo balizado por uma ética aplicada e diretamente relacionada às especificidades preconizadas e necessárias à formação, estará formando biólogos moralmente mais preparados, capazes de lidar com conflitos éticos e dilemas. E, fora do âmbito profissional, é capaz de promover o empoderamento dos cidadãos para que se tornem capazes de promover mudanças sociais, cada vez mais construindo e permitindo que floresça uma sociedade mais justa, inclusiva e libertária.

\section{REFERÊNCIAS}

BRASIL. Diretrizes Curriculares para os cursos de Ciências Biológicas. CNE. Parecer CNE/CES 1.301/2001, Diário Oficial da União de 7 dez. 2001, Seção 1, p. 25, 2001. 
BRASIL. Parâmetros Curriculares Nacionais: terceiro e quarto ciclos: apresentação de temas transversais. Brasília, 1998. Disponível em: <http://portal.mec.gov.br/seb/arquivos/pdf/ttransversais.pdf >. Acesso em: 11 mar 2016.

BRASIL. Resolução $\mathrm{n}^{\circ} 2$, de 15 de junho de 2012. Estabelece as Diretrizes Curriculares Nacionais para a Educação Ambiental. Diário Oficial da União. Brasília: DOU, 2012.

CFBio. Portaria No 177/2015. Estabelece o Regulamento para a concessão do Selo CFBio de Qualidade de Cursos de Ciências Biológicas. Brasília, 2015.

CFBio. Parecer Nº 01/2010. GT REVISÃO DAS ÁREAS DE ATUAÇÃO - Proposta de requisitos mínimos para o biólogo atuar em pesquisa, projetos, análises, perócias, fiscalização, emissão de laudos, pareceres e outros serviços nas áreas de meio ambiente, saúde e biotecnologia. Brasília, 2010.

CZELUSNIAK, Adriana. MEC quer aumentar o número de licenciados no Brasil. A gazeta do povo, 02 out 2011. Disponível em: < http://www.gazetadopovo.com.br/educacao/vida-na-universidade/carreira/mecquer-aumentar-o-numero-de-licenciados-no-brasil-91nyh1sfsy12psp5eb5xgugjy>. Acesso em: 29 mai 2016.

DINIZ, Débora. GUILHEM, Dirce. O que é bioética. São Paulo: Brasiliense, 2002. 69p. (Coleção Primeira Passos).

DÓRIA, Thaís Andrade Ferreira Dória. MOREIRA, Lílian Maria de Azevedo Moreira. A bioética na formação do biólogo: um desafio contemporâneo. Revista FACED, Salvador, n. 20, p. 99-122, jul./dez. 2011, p. 17-36.

CUNHA, Érika Virgílio Rodrigues da. O Currículo e seu planejamento: Concepções e Práticas. Rev. ESPAÇO DO CURRÍCULO, v.3, n.2, pp.578-590, set. de 2010 a mar. de 2011 . Disponível em: <http://periodicos.ufpb.br/ojs2/index.php/rec>. Acesso em: 04 de mar 2016.

FÁVERO, Maria de Lourdes de Albuquerque. A universidade no Brasil: das origens à Reforma Universitária de 1968. Educ. rev., Curitiba, n.28, p.17-36, Dez. 2006. Disponível em: $<$ http://www.scielo.br/scielo.php?script=sci_arttext\&pid=S0104-

$40602006000200003 \&$ Ing=en\&nrm=iso >. Acesso em: 30 mar. 2016.

FLORIOS, Daia. Os 10 alimentos que mais consomem água para serem produzidos. Green me, 22 jul 2014. Disponível em: <https://www.greenme.com.br/consumir/eco-shopping/552-os-10-alimentos-que-maisconsomem-agua> Acesso em: 25 mai 2016.

FRAGA DA SILVA, Paulo. KRASILCHIK, Myriam. BIOÉTICA E ENSINO DE CIÊNCIAS: O TRATAMENTO DE TEMAS CONTROVERSOS - DIFICULDADES APRESENTADAS POR FUTUROS PROFESSORES DE CIÊNCIAS E DE BIOLOGIA. Ciência \& Educação. Bauru, Universidade Estadual Paulista, vol. 19, núm. 2, 2013, p. 379-392.

FREIRE, Paulo. Pedagogia da Autonomia: saberes necessários à prática educativa. 36. ed. São Paulo: Paz e Terra, 2009. 148p.

IBGE, Instituto Brasileiro de Geografia e Estatística. Abate de animais no país é recorde. Agência Brasil, 12 nov 2013. Disponível em: <http://memoria.ebc.com.br/agenciabrasil/noticia/2013-12-11/abate-de-animaisno-pais-e-recorde>. Acesso em 25 mai 2016.

LENOIR, Noelle. Promover o ensino de bioética no mundo. Rev Bioética, Brasília, DF, v.4 n. 1, 1996, p. 6570.

MAAS, Peter. Globally Extinct Birds. 2017. In: TSEW, The Sixth Extinction. Disponível em: <http://www.petermaas.nl/extinct>. Acesso em: 02 set 2018.

MASETTO, Marcos Tarciso. Competência pedagógica do professor universitário. São Paulo: Summus, 2003. $194 \mathrm{p}$.

PAIXÃO, Rita Leal. Bioética e Animais: considerações acerca do sencientismo. In: SGANZERLA, A. (Org.). Fundamentos da Bioética. Curitiba - PR: Editora CRV, $1^{a}$ edição, v. 3, 2016. p. 255-270

PINTO, Gabriela Bertti da Rocha. A ausência da ética animal nas disciplinas de bioética nos currículos do curso de ciências biológicas no Brasil. 2016. 94 f. Dissertação (Mestrado) - Instituto de Saúde Coletiva, Faculdade de Medicina, Universidade Federal Fluminense, Niterói-RJ, 2016. 
POPIM, Regina Célia et al . Câncer de pele: uso de medidas preventivas e perfil demográfico de um grupo de risco na cidade de Botucatu. Ciênc. saúde coletiva, Rio de Janeiro, v.13, n. 4, p. 1331-1336, ago. 2008. Disponível em: <http://www.scielo.br/scielo.php?script=sci_arttext\&pid=S141381232008000400030\&lng=en\&nrm=iso >. Acesso em: 02 set. 2018.

POTTER, Van Rensselaer. Bioética: ponte para o futuro. São Paulo: Edições Loyola, $1^{\mathrm{a}}$ edição, 2016. 280 p.

RIVERO, Sérgio et al. Pecuária e desmatamento: uma análise das principais causas diretas do desmatamento na Amazônia. Nova econ., Belo Horizonte, v.19, n.1, p. 41-66, Abr. 2009. Disponível em: <http://www.scielo.br/scielo.php?script=sci_arttext\&pid=S0103-63512009000100003\&lng=en\&nrm=iso >. Acesso em: 02 set. 2018.

SCHARAMM, Fermin Roland. Bioética para quê? Revista Camiliana da Saúde, ano 1, vol. 1, n. 2 -jul/dez de 2002, p. 14-21.

SILVA, Paulo Fraga da. Bioética e valores: um estudo sobre a formação de professores de ciências e biologia. 2008. 188 f. Tese (Doutorado) - Faculdade de Educação, Universidade de São Paulo, São Paulo, 2008.

. Percepções dos alunos de ensino médio sobre questões bioéticas. 2002. $131 \mathrm{f}$. Dissertação (Mestrado) - Faculdade de Educação, Universidade de São Paulo, São Paulo, 2002.

SILVA, Tomas Tadeu da. Currículo, conhecimento e democracia: as lições e as dúvidas de duas décadas. Cadernos de Pesquisa. São Paulo, n. 73, mai 1990, p. 59-66.

SIMPSON, lan. Gorila é morto após menino cair em área isolada de zoológico nos EUA. Agência Reuters, 29 mai 2016. Disponível em: <http://br.reuters.com/article/worldNews/idBRKCNoYKoMA>. Acesso em: 20 jun 2016.

SINGER, Peter. Ética Prática. São Paulo: Editora Martins Fontes, 2002. 402p.

TRÉZ, Thales A.; LOPES NAKADA, Juliana Isabel. Percepções acerca da experimentação animal como um indicador do paradigma antropocêntrico-especista entre professores e estudantes de Ciências Biológicas da UNIFAL-MG. Alexandria: Revista de Educação em Ciência e Tecnologia, Florianópolis, v. 1, n. 3, p. 3-28, nov. 2008. Disponível em: <https://periodicos.ufsc.br/index.php/alexandria/article/view/37824>. Acesso em: 22 mar. 2016.

TAYLOR, Katy. GORDON, Nicky. LANGLEY, Gill. HIGGINS, Wendy. Estimates for worldwide laboratory animal use in 2005. Alternatives to Laboratory Animals, ed. 36, 2008, pp. 327-342.

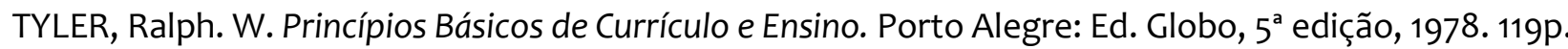

